\title{
LA PROPUESTA SOBRE EDUCACIÓN DE LA COMISIÓN PARA EL ESTUDIO DE LOS PROBLEMAS ESPAÑOLES (1945)
}

\section{The Proposal on Education of the Comission for the Study of the Spanish Problems (1945)}

\section{José Ignacio Cruz Orozco ${ }^{\&}$}

Fecha de recepción: 04/10/2018 • Fecha de aceptación: 10/10/2018

Resumen. En este artículo se analiza y transcribe el texto redactado por un grupo de destacados profesores y pedagogos españoles exiliados, con especial atención a su contextualización. El grupo integraba la ponencia sobre educación de la Comisión de estudio de los problemas españoles, impulsada por la Unión de Profesores Españoles en el Extranjero. El documento final fue publicado en 1945 en la ciudad de México D.F.: en los Talleres tipográficos de B. Costa Amic, y ocupa 23 páginas. Se trata de un auténtico programa de actuación a llevar a cabo tras la restauración de la República en España, que en esas fechas tras finalizar la guerra en Europa, se pensaba cercana.

Palabras clave: Exilio pedagógico; Política educativa; República Española en el exilio.

Abstract. A group of Spanish leading teachers and educators in exile wrote a text which this paper reproduces and analyzes giving special attention to its contextualization. This group incorporated a talk on education from a Study Commission on Spanish problems promoted by the Union of Exiled Spanish Teachers. The final document, containing 23 pages, was published in 1945 in Mexico City by B. Costa Amic publishing company. These pages offer a genuine action plan to be implemented after the restoration of the Republic in Spain, which, in those days after the end of the Second World War, seemed imminent.

Keywords: Pedagogical exile; Educational policy; Spanish Republic in the exile.

\footnotetext{
\& Departamento de Educación Comparada e Historia de la Educación, Facultad de Filosofía y Ciencias de la Educación. Universitat de València. Avda. Blasco Ibáñez, 30. 46010 València, España.jose.i.cruz@uv.es
}

Cómo citar este artículo: Cruz Orozco, José Ignacio. «La propuesta sobre educación de la comisión para el estudio de los problemas españoles (1945)». Historia y Memoria de la Educación 9 (2019): 669-710. 


\section{PRECEDENTES}

La Comisión para el estudio de los problemas españoles apareció en el universo de los exiliados republicanos españoles entre finales de 1943 y comienzos de 1944, aún en plena guerra mundial. Fue impulsada por la Unión de Profesores Universitarios Españoles en el Extranjero (IPEE), entidad creada en París a finales de 1939, a los pocos meses de finalizada la Guerra Civil, por Gustavo Pittaluga, Gabriel Franco, José María Semprún y Alfredo Mendizábal. La Unión contó con una presencia y trayectoria desiguales en diversos países, hasta que sus actividades fueron apagándose lentamente a mediados de los años $50 .{ }^{1}$ En sus inicios estuvo presidida por Gustavo Pittaluga, catedrático de la Universidad de Madrid y reconocido experto nacional e internacional en enfermedades parasitarias, quien, al instalarse en La Habana a principios de 1941, también se llevó consigo la sede de la Unión a la capital caribeña. Aunque al poco tiempo, como el mayor contingente de sus integrantes acabó concentrándose en la ciudad de México, allí se ubicó definitivamente a finales de $1943 .^{2}$

En los primeros momentos, la Unión se conformó como una red de contactos, apoyos y solidaridad entre los profesores universitarios exiliados y sus colegas y conocidos en universidades y centros de investigación en el extranjero. Una entidad especialmente útil y para poder encontrar trabajo y medios de subsistencia en los primeros momentos del exilio. ${ }^{3}$ Pero enseguida, casi desde el mismo momento de su creación, dado el renombre, la trayectoria intelectual y la proyección política de buen número de sus integrantes, y la crucial coyuntura histórica producida por la guerra mundial, también comenzó a jugar un rol como grupo de presión internacional en pro de la restauración de la república española. Un buen ejemplo de ello lo encontramos en la Declaración de La Habana, aprobada en la reunión que la entidad celebró en esa ciudad

\footnotetext{
${ }^{1}$ Para mayor información pueden consultarte los trabajos de Jaume Claret, «La Unión de profesores Universitarios Españoles en el Exilio» y José Ignacio Cruz y Sandra García, «Cuando caiga Franco. Las propuestas educativas para España desde el exilio (1945)», que se publican en este mismo monográfico.

2 José María López Sánchez, «El exilio científico republicano en México: la respuesta a la depuración», en La destrucción de la ciencia en España. Depuración universitaria en el franquismo, dir. Luis Enrique Otero Carvajal, (Madrid: Editorial Complutense, 2006), 177-239.

${ }^{3}$ Francisco Javier Dosil Mancilla, «La JAE peregrina», Revista de Indias 57, no. 239 (2007): 307332.
} 
en octubre de 1943, un par de años antes de que se reunieran las Cortes republicanas o se creara el gobierno en el exilio.

El documento tomaba como punto de partida uno de los principios enumerados en la Carta del Atlántico (1941), destacada declaración política firmada por el primer ministro británico Churchill y el presidente de los Estados Unidos Roosevelt. En concreto, se fundamentaba en el punto tres de esta en el que los firmantes se comprometían a respetar la libertad de los pueblos a escoger libremente «la forma de gobierno bajo la cual quieren vivir», y expresaban su deseo de que fueran "restablecidos los derechos soberanos y el libre ejercicio del gobierno a aquellos a quienes les habían sido arrebatados por la fuerza».4

Tomando esa formulación como base, y aplicándola a la situación española, el texto aprobado por los universitarios españoles señalaba en su base undécima: "Que España se considera con derecho, como reparación justiciera, a obtener el decidido apoyo moral de las Naciones Unidas para recobrar su libertad». ${ }^{5}$ Unos planteamientos que, como acertadamente se ha señalado, fueron producto del «optimismo y la esperanza», basados en la trascendencia que «el curso de la guerra mundial podían tener para el futuro de España». ${ }^{6}$ La Declaración ha sido considerada una de las primeras toma de posición, si no la primera, de espectro amplio y sin tintes partidistas, para conseguir el regreso de la República a España dentro del convulso escenario bélico internacional de aquellas fechas. ${ }^{7}$

\section{LA COMISIÓN. FORMACIÓN}

Pero no fue esa la única conclusión de la reunión de La Habana, los asistentes también acordaron desarrollar algunas iniciativas más operativas $\mathrm{y}$, sin abandonar el registro universitario e intelectual que les ca-

\footnotetext{
${ }^{4}$ Juan Carlos Pereira y Pedro Antonio Martínez, Documentos básicos sobre Historia de las Relaciones Internacionales (1815-1991) (Madrid: Editorial Complutense, 1995), 306-307.

5 «Declaración de La Habana de la Primera Reunión de Profesores Universitarios Españoles», Boletín Informativo de la Unión de Profesores Universitarios Españoles en el Extranjero (Sección México) 2-5, (1943): 9-11.

' López Sánchez, «El exilio científico republicano en México», 209.

${ }^{7}$ Alicia Alted, La voz de los vencidos. El exilio republicano de 1939 (Madrid: Aguilar, 2005), 321-322. $\mathrm{Y}$ «Declaración de La Habana», 9-11.
} 
racterizaba, organizaron tres ponencias para estudiar y redactar propuestas más concretas, a modo de programa de actuación para cuando se produjera el regreso a España. La primera dedicada a Problemas de Educación y Cultura, la segunda centrada en los Problemas sociales y la tercera con el cometido de estudiar los Problemas jurídicos y económicos. En ellas se inscribieron algo más de una docena de miembros de la Unión, a quienes se sumaron algunos licenciados, auxiliares universitarios, maestros y profesores de segunda enseñanza exiliados en Cuba. De la primera, que es la que guarda relación directa con nuestro trabajo, fueron responsables el profesor de filosofía Joaquín Xirau, que entre 1933 y 1939 había sido decano de la Facultad de Filosofía y Letras de la Universidad de Barcelona, Cándido Bolívar, notable entomólogo y catedrático de zoología en la Universidad de Madrid, y Francisco Giral, catedrático de farmacia en la Universidad de Salamanca. Los tres aunaban a su brillante carrera profesional una amplia presencia pública. ${ }^{8}$

Como se indicó, a finales de 1943 la sede de la Unión se trasladó a la ciudad de México. Coincidiendo con el cambio se impulsaron los trabajos pendientes, de lo cual se dio cuenta en una asamblea celebrada el 8 de agosto de 1944 en la sede del Ateneo Ramón y Cajal, una de las primeras entidades socio-profesionales creadas por los republicanos españoles en tierras mexicanas, ubicada en el centro histórico de esa capital. En relación con las ponencias, se indicó que a principios de año se había convocado a los dirigentes del Ateneo, la Federación de Trabajadores de la Enseñanza (FETE) y la Agrupación de Escritores y Periodistas Republicanos, únicas entidades intelectuales de los exiliados en activo por aquellas fechas, con el objeto de reconstituir la comisión, ahora denominada Comisión para el estudio de los problemas españoles. Si la denominación había sufrido variaciones su objetivo no había mudado, y seguía consistiendo en elaborar un programa de actuación «que pueda ser de utilidad cuando comience la tarea de reconstrucción de España en todos sus aspectos bajo un régimen de libertad y justicia». ${ }^{9}$

\footnotetext{
8 «Declaración de La Habana», 12-13. Marta Nogueroles Jové, «La propuesta pedagógica de Joaquín Xirau», Transatlántica de educación 14-15 (2015): 41-53. Y http://cienciadeacogida.org/es/expo/ protagonista/candido-bolivar-pieltain/.

9 Alicia Alted Vigil y Roger González Matell, «Científicos españoles exiliados en Cuba», Revista de Indias 22, no. 224 (2002): 173-194, y "Asamblea General de la U.P.U.E.E.», Boletín Informativo de la Unión de Profesores Universitarios Españoles en el Extranjero (Sección México) 13-14 (1944): 2-6. Con posterioridad se incorporaron a los trabajos otras dos entidades: La Federación de Funciona-
} 


\section{LOS INTEGRANTES}

La Comisión quedó formada con dos delegados de cada una de las cuatro entidades, las tres citadas más la Unión, y una de sus primeras tareas consistió en elaborar un listado de temas sobre los que centrar los trabajos, para posteriormente comenzar a designar responsables. En concreto, se constituyeron ponencias para estudiar los problemas en: educación; constitución y leyes fundamentales; sanciones y reparaciones; alimentación; sanidad; ejército; religión; agricultura; industria y reconstrucción económica. La coordinación de la primera fue propuesta a Francisco Barnés, profesor estrechamente vinculado a la Institución Libre de Enseñanza que había sido ministro de instrucción pública durante la II República, quien declinó el encargo por problemas de salud. Finalmente, la responsabilidad recayó en el profesor Joaquín Xirau, el cual contó con la colaboración de Francisco Giral, Enrique Rioja, Rubén Landa, Luis Santullano, Antonio Ballesteros, Pedro Martín Navarro, José Peinado Altable y Domingo Tirado Benedí.

Se trataba de un conjunto muy selecto de destacados pedagogos y profesores, especialistas en las diversas etapas del sistema educativo con una amplia y brillante trayectoria profesional. Cuatro de ellos Santullano, Ballesteros, Peinado y Tirado- habían sido durante años maestros, inspectores o profesores de escuelas normales, por lo que contaban con un amplio conocimiento de la realidad de la escuela primaria y sus problemas más destacados. Otros tres —Landa, Xirau y Rioja - acumulaban una amplia experiencia en el bachillerato, y tanto Xirau como Rioja habían culminado su carrera docente en la universidad. Por su parte, Giral, tal como se señaló, era catedrático de universidad, además de secretario de la Unión.

Pero quizá el rasgo más nítido que se atisba en sus trayectorias, y del cual quedó amplia constancia en los trabajos que realizaron, fue su vinculación con la Institución Libre de Enseñanza (ILE). Todos habían tenido contacto con las iniciativas institucionistas y compartían en gran medida su ideario reformista. Pero esa impronta resultaba especialmente intensa en Landa, Santullano, Ballesteros y Peinado, sobre todo

rios Públicos y la Fundación Universitaria Escolar (López Sánchez, «El exilio científico republicano en México», 227). 
en los dos primeros. Landa, por ejemplo, había trabajado durante años en la secretaría de la Junta de Ampliación de Estudios (JAE), había sido maestro de la Sección-Preparatoria del Instituto-Escuela de Madrid y estaba considerado, además, fiel discípulo de Manuel Bartolomé Cossío. Santullano, por su parte, también fue un íntimo colaborador de Cossío, trabajó durante años en la Junta y ocupó los cargos de secretario y vocal del Patronato de Misiones Pedagógicas, siendo uno de los mayores impulsores de este proyecto socio-cultural. ${ }^{10}$

Otra influencia destacada que se localiza entre los integrantes de la comisión, es la socialista. Xirau, Ballesteros y Tirado mantuvieron vínculos relevantes con diversas organizaciones de esa ideología. El primero había sido uno de los fundadores de la Unión Socialista de Catalunya. Ballesteros, por tu parte, estuvo íntimamente ligado a la Federación de Trabajadores de la Enseñanza (FETE), la organización que agrupaba a los docentes dentro de la central sindical UGT, tanto durante su etapa en España como durante los primeros años de su exilio en México. Tirado, también estuvo muy vinculado a esa Federación, de cuyo comité de dirección formó parte durante un tiempo. ${ }^{11}$

\section{PUBLICACIÓN}

La ponencia siguió un sistema de trabajo muy descentralizado y participativo. El texto final fue el resultado del trabajo común llevado a cabo por sus integrantes, aunque no solo por ellos. Los miembros de las restantes ponencias también fueron conociendo, discutiendo y realizando aportaciones a los sucesivos borradores. No es posible por tanto atribuir autorías concretas, más allá del voto particular de Xirau al que se adhirió Giral, relacionado con la enseñanza religiosa y que se incorporó al final del dictamen. Excepto por esa cuestión parcial más específica, el resultado final debe considerarse básicamente como el trabajo

\footnotetext{
${ }^{10}$ Eugenio Otero Urtaza, «Los marineros del entusiasmo en las Misiones Pedagógicas», en Las Misiones Pedagógicas, 1931-1936, ed. Eugenio Otero Urtaza (Madrid: Sociedad Estatal de Conmemoraciones Culturales-Residencia de Estudiantes, 2006), 64-113.

11 José Luis Martín Ramos, «La Unió Socialista de Catalunya (1923-1936)», Recerques: Història, economia i cultura 4 (1974): 155-190, Modesto Miguel Rangel Mayoral, Rubén Landa Vaz. Un pedagogo extremeño de la Institución Libre de Enseñanza en México (Mérida: Editorial Regional de Extremadura, 2006), y Francisco de Luis Martín, La FETE (1939-1982). De la represión franquista a la transición democrática (Madrid: Tecnos, 2009).
} 
conjunto de ese reducido pero significado grupo de profesores y académicos.

El documento fue publicado en forma de folleto en 1945 en la capital mexicana. Aunque en la portada figura como autora la Comisión de Estudio de los Problemas Españoles, en la pequeña introducción explicativa que figura en las páginas iniciales se relacionan todos los componentes de la ponencia, los cuales deben ser considerados a todos los efectos como los auténticos responsables del trabajo realizado y redactores del texto. La edición se compuso en los talleres tipográficos B. Costa i Amic, una de las razones comerciales empleadas por el notable impresor catalán Bartolomeu Costa i Amic, dirigente del troskista Partido Obrero de Unificación Marxista (POUM) y compañero de exilio de los miembros de la Comisión. ${ }^{12}$

A la puerta de Costa i Amic acudieron muchos republicanos españoles sin distinción de ideología para publicar sus originales, ya fueran académicos, profesionales, políticos o memorialísticos. Por tanto, resulta bastante frecuente encontrar su pie de imprenta en un buen número de los trabajos editados por estos en México, tanto en castellano como en catalán. Independientemente de esa cuestión, Costa i Amic llevó a cabo en México una tarea de difusión cultural muy destacada, poniendo al alcance del mexicano medio un buen número de títulos, que ha sido repetidamente reconocida. ${ }^{13}$

De los trabajos de las demás ponencias que integraban la Comisión, apenas tenemos noticias. A la par que el dictamen sobre Educación, se publicó otro titulado «Anteproyecto de Carta Política Transitoria: Organización y Funcionamiento» de una extensión de 18 páginas. ${ }^{14} \mathrm{~A}$ buen seguro debe tratarse del dictamen correspondiente a las ponencias sobre constitución y leyes fundamentales y sanciones y reparaciones, que se habían constituido a mediados de 1944, al mismo tiempo que la de educación.

\footnotetext{
12 Aunque falleció en la Ciudad de México en 2002, sus hijos han continuado con la empresa que aún se encuentra en activo hoy en día. https://web.archive.org/web/20150909162108/http://www. fundanin.org/costa-amic.htm

${ }^{13}$ En 1986 fue distinguido con la Creu de Sant Jordi por la Generalitat de Catalunya https:// altrescostaamic.wordpress.com/about/historia/

${ }^{14}$ Comisión de Estudio de los Problemas Españoles, Anteproyecto de Carta Política Transitoria: Organización y Funcionamiento (México: s.e., 1945).
} 


\section{EL CONTENIDO EN SU CONTEXTO}

El texto de la ponencia sobre educación se publicó en forma de folleto, al menos con un ejemplar de ese formato es con el que hemos podido trabajar, el cual consta de 23 páginas. El documento se estructura en una introducción, un apartado de normas generales, otro dedicado a la enseñanza primaria, un tercero sobre la enseñanza media, el siguiente centrado en la cultura superior y con un último apartado con el epígrafe; Intercambio universitario y relaciones culturales, especialmente con América. El documento finaliza con la exposición del ya citado voto particular del profesor Xirau, al que se adhirió Francisco Giral.

En cada uno de los apartados se enumeraba una serie de propuestas relativamente concretas. Los de normas generales y primera enseñanza incluyen 19 medidas; el de enseñanza media 29; el de educación superior 31 dedicadas a universidades y escuelas superiores, a los que había que añadir 5 a la investigación científica y 4 al tesoro histórico-artístico y servicios de Archivo, Bibliotecas y Museos. En el último apartado dedicado al intercambio universitario se especificaban 6 medidas, aunque la última de ellas se concreta, a su vez, en 13 objetivos más particulares. En su conjunto se trata de unas propuestas de interés, bastante bien meditadas y articuladas, redactadas por un grupo de personas, varones todos ellos, con un dilatado recorrido profesional en distintas etapas del sistema educativo y una más que notable trayectoria de responsabilidades públicas.

No vamos a entrar en el análisis de sus contenidos, que efectuamos en otro lugar de este mismo monográfico. ${ }^{15}$ Pero sí queremos destacar que el dictamen se publicó en un contexto crucial desde muchos puntos de vista. Desde una perspectiva global, entre abril y junio de ese mismo año se celebró la Conferencia de San Francisco, en donde se aprobó la Carta de las Naciones Unidas, una de las vigas maestras sobre las que se articularía la política internacional de la postguerra mundial.

Teniendo en cuenta esa coyuntura, las fuerzas republicanas españolas realizaron importantes esfuerzos por ganar presencia política y conseguir que sus demandas tuvieran la mayor visibilidad posible, en esas

\footnotetext{
15 José Ignacio Cruz y Sandra García de Fez, «Cuando caiga Franco. Las propuestas educativas para España desde el exilio, 1945».
} 
fechas en las cuales las potencias aliadas estaban diseñando el mapa de la Europa de la posguerra. Con esa finalidad se reconstituyeron las Cortes Republicanas, las cuales celebraron varias reuniones en enero, agosto y noviembre de 1945 en la capital mexicana. Su actividad principal se centró en cuestiones internas, especialmente intentando conciliar los intereses en que estaban divididos los grupos políticos y buscando compromisos para poder constituir un gobierno en el exilio. ${ }^{16}$

Finalmente, en noviembre de 1945 se consiguió formar el primer gobierno de la república en el exilio —el denominado de la esperanzapresidido por José Giral, precisamente uno de los puntales de la Unión. Al principio tuvo su sede en el Distrito Federal mexicano, pero en la primavera del año siguiente se trasladó a París, con la esperanza de ganar eficacia en su objetivo primordial de alcanzar un cambio de régimen en España y conseguir el ansiado regreso. ${ }^{17}$ En medio de estas circunstancias, ni las Cortes, ni posteriormente el gobierno de Giral, ni los que le sucedieron, elaboraron documento alguno que guarde alguna similitud con el que estamos analizando.

El texto de la ponencia debe situarse en ese contexto concreto y adquiere mayor relevancia y significación si lo comparamos con la escasa eficacia de las instituciones y los partidos republicanos para redactar un programa de actuación similar. Frente a esa manifiesta debilidad, la ponencia nos muestra con bastante claridad y relativo detalle, cuáles eran los proyectos de intervención en el espacio de la política de la educación planteados por un significativo colectivo de republicanos de diversas orientaciones ideológicas y una amplia trayectoria como profesionales de la enseñanza.

Hasta donde sabemos, es el único documento sobre política educativa, elaborado con un espíritu de consenso relativamente amplio, que iba más allá de las formulaciones estrictamente partidistas, por las entidades, instituciones, partidos o grupos republicanos que componían el exilio republicano español de 1939. Se trata de un programa de intervención relativamente amplio que permite conocer matices y plan-

\footnotetext{
16 Alted, La voz de los vencidos, 321, y Francisco Giral, «Actividad de los gobiernos y de los partidos republicanos», en El exilio español de 1939, vol. II, dir. José Luis Abellán (Madrid: Taurus, 1976), 204-207.

17 Giral, «Actividad de los gobiernos», 207-210.
} 
teamientos de un significativo sector de éste. Pese a su importancia, y aunque fue publicada, la ponencia es prácticamente desconocida, quizá debido a que la Unión era una entidad ubicada más en el ámbito profesional que en el político, y que los acontecimientos posteriores dejaron a toda la propuesta en barbecho, convertida en un mero proyecto que nunca no pudo ser llevado a la práctica.

De su lectura se desprende con mucha claridad, que el impulso modernizador de la educación republicana no había decaído, pese a la derrota y el exilio. Sorprende la actualidad de muchos de los principios que impulsó la ponencia — coordinación e integración del sistema educativo; ampliación de la escolarización; igualdad entre el hombre y la mujer; reivindicación de la pedagogía; libertad de conciencia; relectura integradora de la conquista de América; intercambios internacionales, entre otros aspectos- plenamente vigentes hoy en día, ya bien entrados en el siglo xxi y a ocho décadas del exilio pedagógico español de 1939. 


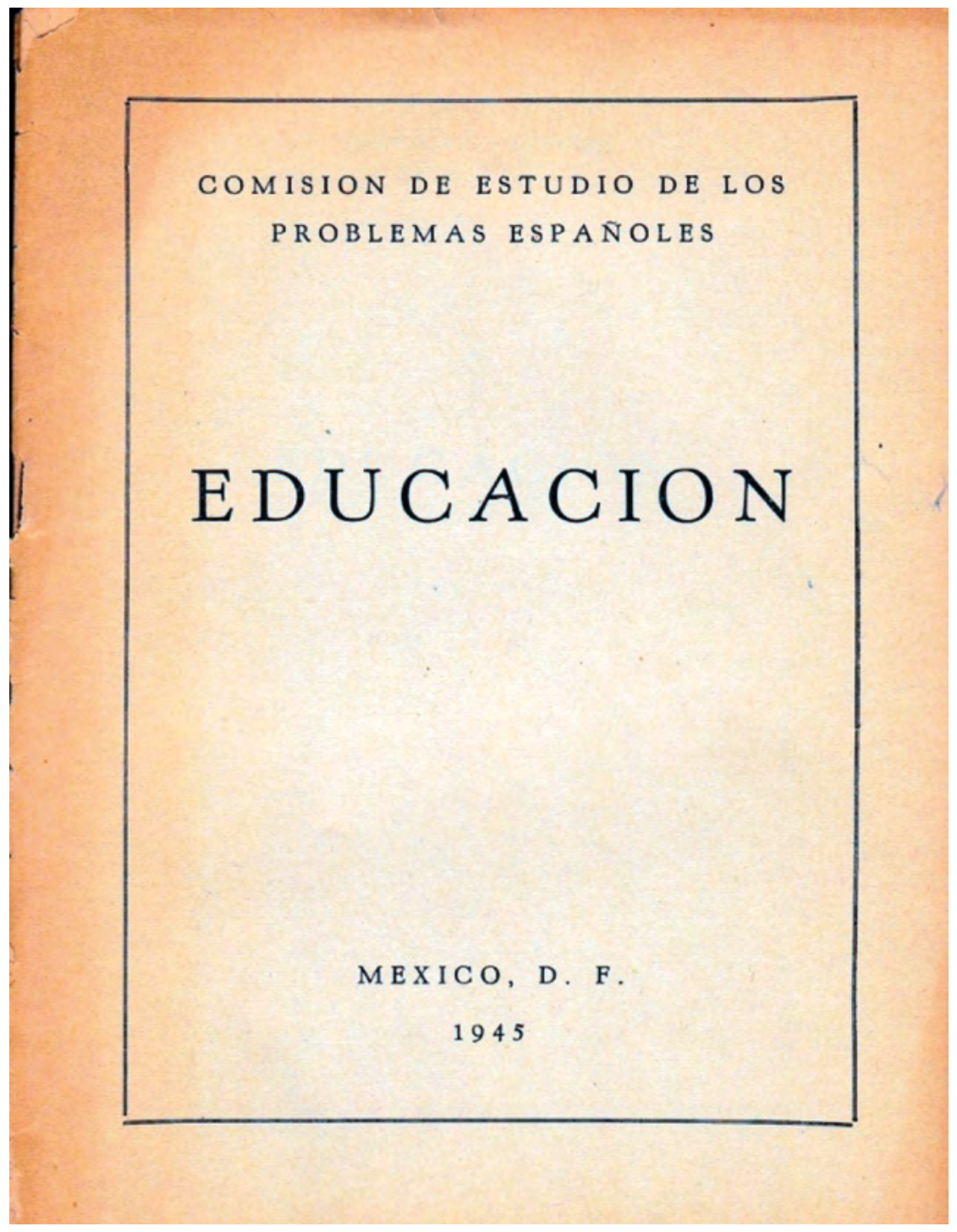

Comisión de Estudio de los Problemas Españoles, Educación (México D F: Talleres tipográficos de B. Costa Amic, 1945) 23 páginas

La dirección de la Ponencia sobre EDUCACIÓN estuvo encomendada al Dr. Joaquín Xirau y en su preparación intervinieron los Sres. Francisco Giral, Enrique Rioja, Rubén Landa, Luis Santullano, Antonio Ballesteros, Pedro Martín Navarro, José Peinado Altable y Domingo Tirado Benedí. Fué examinada, discutida y aprobada en Asambleas Generales de Representantes de las Entidades que forman la Comisión de Estudio de los Problemas Españoles. 


\section{COMISIÓN DE ESTUDIO DE LOS PROBLEMAS ESPAÑOLES}

\section{EDUCACIÓN}

\section{INTRODUCCIÓN}

Es, ante todo, preciso advertir que la totalidad de lo que a continuación se expone ha sido pensado para una situación en que exista un mímimun de continuidad histórica y de normalidad, en vista de un estado de cosas en el cual quede algo de lo que en la tradición secular ha hecho de España lo que es. Para cualquier otra hipótesis, todo sería imprevisible y habría que confiarlo, o a la improvisación o a la imperfecta aplicación de esquemas abstractos, siempre a merced de las reacciones empíricas y de los obstáculos invencibles a que siempre da lugar la falta de preparación y de previsión. Para una situación de esta índole todo es fácil o difícil o aun, acaso, imposible. Todo depende del sentido de responsabilidad de aquellos que traten de ejecutarlo. Fácil es concebir un plan ideal. No hay más que acudir a la feria. No proponemos una acción quirúrgica. Si fuese imprescindible, que Dios ponga tiento en las manos que la ejecuten. Nos limitamos a una ordenación terapéutica y de vigorosa higiene.

Esto supuesto, en todos los grados de la enseñanza es preciso discerner entre el ideal, solo parcialmente realizable, y las soluciones de urgencia propuestas con plena conciencia de su imperfección. Sólo debe intentarse lo que aquél aconseje, allí donde las condiciones reales y, muy especialmente, la preparación de las personas, ofrezcan garantías de éxito, es decir, en circunstancias y núcleos restringidos y bien seleccionados, con objeto de que, aparte su función directiva, sirva lo alcanzado de modelo y ejemplo, y sea fermento de constante renovación.

Las indicaciones que siguen no se refieren, por tanto, a los núcleos de selección que en todos los grados de la enseñanza existían ya en España y se desarrollaron durante la República. Ante ellos, lo único que cabe hacer es seguir fomentándolos, y multiplicarlos con tacto y cautela, siempre que las circunstancias lo permitan. Tienen su ley interna. Cualquiera imposición exterior les sería perjudicial. Así, en la primera enseñanza, las Escuelas Modelo de Madrid, Barcelona, León, Mallorca, 
etc.; en la enseñanza elemental y media la Institución Libre de Enseñanza, los Institutos-Escuela, etc.; en la enseñanza superior, los centros de alta investigación de Madrid y Barcelona, y las reformas establecidas por la autonomía de la Universidad de Barcelona, de las Facultades de Filosofía y Letras y, dentro de ciertos límites, de Medicina de Madrid.

Las reformas que proponemos son de carácter general y urgente, y aconsejables no sólo para los centros dependientes del poder central sino también, y salvando toda jurisdicción, para los de las corporaciones autónomas, y no aspiran, en substancia, a otra cosa que a establecer el nivel mínimo en todos los establecimientos del país, procurando que éstos sean suficientes en cantidad y, en calidad, por lo menos, decorosos.

La experiencia de las reformas introducidas y consolidadas en los centros de selección, y el minucioso conocimiento de cada uno de los demás, aconsejarán en todo momento sobre la posibilidad de la gradual introducción de aquéllas en la economía normal de la enseñanza. Todo siempre con sumo tacto y cautela, evitando el menor asomo de arbitrismo irresponsable, y no haciendo nunca más que aquello que, con plena eficacia, ofrezca garantías de viabilidad. Nada más absurdo que la superstición de la ley y la reforma en el papel.

No hay que perder de vista en momento alguno la necesidad de la coordinación de todos los grados de la enseñanza, evitando toda fácil "planificación" abstracta, tendiendo, por el contrario, a una armonía orgánica y vital que respete todas las asimetrías indispensables para el sano crecimiento y no olvidando la unidad de esencia de la primera y segunda enseñanza, que forman un todo con plena substantividad, frente a la superior y técnica. Trátase en ellas de la formación del hombre en su plenitud humana, con independencia de la especial consagración que ulteriormente le sea deparada a cada cual. De ahí la necesidad de aspirar a que la segunda enseñanza sea posible para todos, y, en tanto ésto no se consiga, la urgencia no sólo de establecer su carácter gratuito, sino de conceder becas abundantes para facilitar el acceso a ella de los mejor dotados, y asegurar así la consiguiente selección a medida que se asciende en los grados. De ahí también la conveniencia del establecimíento provisional de un bachillerato para 
obreros, con el objeto de corregir, en.alguna medida, las deficiencias del sistema de privilegio que hemos heredado. Por idéntica razón debe tenderse a que la orientación vocacional definitiva se realice lo más tarde posible, siempre que las circunstancias lo permitan o lo aconsejen.

La enseñanza en todos los grados tendrá una orientación liberal y democrática, es decir, alejada de todo dogmatismo y de toda imposición doctrinaria, de acuerdo con lo que se establezca en la Constitución y en las leyes. En la primera y media, esto deberá entenderse en el sentido de establecer la garantía de íntegro respecto a la conciencia del alumno y del maestro, evitando en la escuela todo aquello que pueda representar una escisión entre las personas o una vejación para cualquiera de ellas. Ello no significa neutralidad en el sentido de indiferencia. Supone solo apartamiento de toda imposición. Así, será excluída de la escuela toda enseñanza dogmática, en el orden confesional y filosófico, dejando a las familias y a las Iglesias la decisión acerca de tan graves asuntos. En la escuela no serán excluídas ni la Filosofía ni la Religión; por el contrario, serán explicadas, desde el punto de vista histórico, con el respeto que merecen y requieren su dignidad en el espíritu y en la cultura, sin que ello suponga la institución de cátedras especiales. En lo político y social, la escuela se limitará a exponer y aclarar, con la misma libertad y amplia simpatía humana, los preceptos de la Constitución del Estado, relacionándolos con los problemas de la realidad y con las grandes tendencias doctrinales.

En estas condiciones, el Estado tiene el deber de proveer a todas las necesidades del país, en lo relativo a la enseñanza primera y media, procurando que sus escuelas sean, en todos los aspectos, las mejores.

Previo este requisito y el reconocimiento de este deber urgente, nada aconseja, antes al contrario, el establecimiento del monopolio del Estado en la enseñanza.

El Estado debe crear escuelas con la mayor rapidez que las circunstancias permitan. No debe suprimir, sin embargo, ninguna enseñanza privada mientras no se halle en condiciones de dar otra mejor. La experiencia personal nos ha demostrado que, dondequiera que ésto ha sido posible, la escuela privada ha cerrado automáticamente sus puertas. No 
hay que exponer nunca al Estado a una comparación desigual y al consiguiente desprestigio.

De otra parte, sin contravenir los principios antes expuestos es conveniente y aun beneficiosa la existencia de escuelas libres que sirvan a las del Estado de aliciente y de acicate. El Estado intervendrá en este caso para garantizar la normal función docente de los centros privados, exigiendo títulos de suficiencia al personal que profese en ellos, para garantizar la competencia, la moralidad, la higiene y el respeto a los alumnos y a los maestros. Intervendrá, además, el Estado con el fin de exigir, para la obtención de certificados y títulos, un nivel de formación y cultura deseable, mediante exámenes amplios, rigurosos y razonables, ante profesores oficiales, evitando las pruebas rutinarias y por asignaturas y buscando valorar la competencia con pruebas de conjunto, predominantemente escritas. Se podrá eximir de título, en casos excepcionales de superior y reconocida competencia.

En los grados superiores de la enseñanza debe regir la más absoluta libertad espiritual para profesores y alumnos. No es conveniente, en cambio, permitir que se organicen por entidades particulares que, dado el estado actual de España, no pueden en modo alguno ofrecer garantías de responsabilidad y competencia y que fácilmente se convertirían en organizaciones financieras orientadas en el lucro o en centros de propaganda sectaria, ajena a los altos intereses de la cultura superior. En relación con ésto, se plantea el problema de la autonomía universitaria. No cabe duda de que, en principio, la autonomía es un bien. A ella hay que dirigirse sin vacilar. Hay que tener, sin embargo, clara conciencia de que implantarla de pronto, impulsivamente, sin tener en cuenta la escasez de fuerzas espirituales y materiales de la mayoría de las Universidades españolas, podría traer consigo las más desastrosas consecuencias. Es necesario a nuestro juicio mantener íntegramente el régimen de autonomía de que gozó la Universidad de Barcelona e implantar con urgencia un régimen análogo en la de Madrid, teniendo en cuenta, en ambos casos, que nadie es autónomo mientras no posea los medios materiales para vivir por sí mismo.

Las indicaciones que a continuación se dan no se refieren al regimen interno de las Universidades que así se rijan. Tienden más bien a 
indicar aquello que es preciso hacer en las demás, para que gradualmente, tuteladas con amor y sentido de responsabilidad, adquieran el vigor y la clara conciencia que permita, a la larga, la autonomía a que se aspira.

Un caso hay que considerar con especial atención. Se trata de la Universidad de Salamanca. Mantenerla en su estado actual es para todos una vergüenza. A esa Institución hay que consagrar un cuidado especial en razón de su prestigio histórico y de los gérmenes vitales que todavía, a pesar de todo, mantiene. Un régimen de autonomía, con un Patronato análogo al establecido en la Universidad de Barcelona, sería, acaso, el mejor camino para tratar de restablecer progresivamente a Salamanca, procediendo siempre con tacto y medida, la aureola de ciudad universitaria de que gozó.

Así tendríamos una Universidad castellana, una Universidad catalana y una Universidad equidistante donde merecieran proporcional atención todas las orientaciones del espíritu y de la cultura que se han desarrollado y se desarrollan en la Península.

Las recomendaciones articuladas que damos a continuación se refieren, por tanto, a todas las demás.

La divulgación científica y la alta investigación — pura y aplicadaserán, naturalmente, libres dentro de los límites de la moralidad y de la ley.

Esto supuesto, es preciso sustraer la forma y la constante renovación de los establecimientos de enseñanza al cambio frecuente de las circunstancias políticas, encomendándolas, con carácter de continuidad y persistencia, a un grupo de personas, siempre reducido, sin distinción de partidos políticos, escogidas entre aquellas que se hayan distinguido por su competencia en los problemas de la educación y por su rectitud y solvencia moral. Es preciso acabar con la perniciosa influencia que ejercen en la organización de la enseñanza las constantes luchas de los partidos políticos y religiosos. El Consejo Nacional de Cultura, convenientemente reorganizado y dando en él entrada a elementos de representación social, podría ser el núcleo esencial de aquel organismo permanente. Sin la garantía de continuidad es inútil, o poco menos, toda reforma que se intente. Cual- 
quier plan de realizaciones sucesivas supone una proyección a largo plazo, y lo que puede ser utilísimo como parte de una transformación total y gradual, sería inútil y aun contraproducente si se le privase de esas circunstancias.

Lo primero y más urgente en todos los grados de la enseñanza es el perfeccionamiento del personal existente y la formación del nuevo. Programas, métodos y organización deben venir después, porque no tendrían valor alguno sin la garantía del maestro. Para atender a esa necesidad, aparte las normas que proponemos en cada grado, será preciso en todos ellos continuar la política de pensiones al extranjero, procurando dotarla de una tutela adecuada y de una rigurosa dirección por organismos especiales que le impriman carácter orgánico y coordinado.

Téngase en cuenta que las normas que a continuación se proponen deben ser comunes a la educación de la mujer y a la del hombre, la formación de los cuales debe organizarse, en principio, en régimen de coeducación. Claro que, en este aspecto, como en todos, hay que proceder con cautela y de tal manera que lo que es en sí mismo excelente no resulte contraproducente. La coeducación bien dirigida es, sobre todo aconsejable desde el punto de vista de una sana moral. Y en España la coeducación tiene antecedentes ejemplares.

La enseñanza en todos los grados debe substituir los procedimientos que permiten sólo la adquisición de un saber verbal, por aquellos que postulan el aprendizaje por el trabajo práctico, por métodos objetivos, a base de observación, experiencia, e intuición directa. Y se procurará enriquecer la apetencia espiritual, el deseo de conocer las más variadas y bellas cosas del mundo, fomentando y facilitando las excursiones, viajes al extranjero, visitas a museos, talleres y fábricas, uso de bibliotecas, etc., sin olvidar la fundamental importancia que se habrá de conceder a la organización eficaz de la educación física de la juventud en todos sus aspectos.

En todos los grados de la enseñanza es preciso establecer colonias escolares de vacaciones, especialmente destinadas a los niños pobres, y colonias permanentes de montaña y de mar, para los de salud deficiente. 
Con el objeto de coordinar los servicios del Estado central con los de las corporaciones autónomas y evitar, en la medida de lo posible, la dualidad de las enseñanzas, es necesario establecer en las regiones autónomas Consejos de la Educación con secciones primaria y secundaria, con las facultades consultivas y ejecutivas que tenga, en lo general, el Consejo de Educación Nacional, reformado de acuerdo con las anteriores indicaciones. Uno de los beneficios de estos Consejos sería también sustraer la enseñanza a los vaivenes de la política cotidiana. En el aspecto universitario y en este respecto, no habrá más que restablecer la autonomía que tuvo la Universidad de Barcelona y que tan excelentes resultados dio.

\section{NORMAS GENERALES}

1. Se reanudará y proseguirá la obra realizada por la República en el dominio de la instrucción y educación públicas.

2. La enseñanza en todos sus grados, habrá de tener una orientación liberal alejada de cualquier tipo de imposición dogmática.

3. La enseñanza religiosa confesional pertenece a las Iglesias y se dará con toda libertad, bajo la inspección del Estado. En la enseñanza primaria y media se considerará necesaria la explicación de la filosofía y de la religión desde el punto de vista histórico, tratando los asuntos con todo el respeto que merecen su dignidad en el espíritu y en la cultura.

4. En lo político y social la escuela expondrá y esclarecerá, con la misma libertad y amplia simpatía humana, los preceptos de la Constitución del Estado, poniéndolos en contacto con los problemas de la realidad y con las grandes tendencias doctrinales.

5. Se procurará establecer una conveniente relación en todos los grados de la enseñanza, haciendo efectivo el principio de la unificación docente.

6. Aunque sea función del Estado proveer a todas las necesidades docentes del país, se considera conveniente y aun beneficiosa, la colaboración de instituciones privadas en la primera enseñanza y en la media, siempre que ofrezcan, a juicio del Estado, rigurosas garantías de res- 
peto a la conciencia de los alumnos y maestros, de moralidad e higiene, de capacidad en el profesorado y de un nivel suficiente alcanzado por los alumnos.

7. Cualquier reforma en el dominio de la instrucción pública habrá de efectuarse solamente allí donde las circunstancias, los medios y la existencia de personal adecuado ofrezcan garantías de eficacia.

8. Para sustraer la función docente a la influencia de los cambios políticos, será conveniente crear un organismo rector, con amplias atribuciones, que garantice la continuidad del espíritu progresivo de los centros de educación en general.

9. Se considera factor de atención urgente, para la organización y progreso de la enseñanza, el perfeccionamiento del personal existente y la formación del nuevo. Con ese fin deberán movilizarse los recursos y el per sonal necesario para adscribirlos a esa función.

10. Como orientación y para su realización progresiva, se declara la conveniencia de organizar los centros de enseñanza de todos los grados en régimen de coeducación.

11. Es de recomendar que la coordinación de la política de cultura del Estado central con la de los gobiernos autónomos se lleve a cabo mediante Consejos mixtos de enseñanza.

12. La enseñanza en todos sus grados debe tener un sentido activo, personal y tutelar, de íntima convivencia entre el maestro y el alumno, que atienda armónicamente a la formación intelectual moral, estética y física de los educandos.

13. En todos los grados de enseñanza es preciso organizar equipos de intercambio nacionales e internacionales y crear cantinas y colonias escolares permanentes y de vacaciones, estableciendo todas las garantías necesarias para el goce equitativo de sus beneficios.

14. Lo mismo en la enseñanza secundaria que en la técnica media, normal y superior, conviene extender el sistema de Residencias de estudiantes, teniendo en cuenta la organización de las establecidas en Madrid y los ensayos realizados en Barcelona. 
15. Sería conveniente reanudar los ensayos originales realizados por las escuelas plurilingües de Madrid y desarrollarlos de modo experimental en uno o varios de los establecimientos docentes de la nación.

16. Con el fin de procurar una mayor armonía y compenetración de los distintos pueblos que viven en la península ibérica, se considera conveniente la introducción gradual y con carácter voluntario [de] las enseñanzas de lengua galaico-portuguesa y de lengua catalana en el bachillerato, y establecer en Madrid y otras Universidades estudios superiores de filología y cultura galaico-portuguesa, catalana y vasca.

17. Se declara que la falta de medios económicos en los estudiantes de cualquier grado de enseñanza, no debe representar nunca una imposibilidad de acceso a los centros docentes, siempre que se demuestre capacidad suficiente.

18. Se reconocerá, dentro de los límites y condiciones que se establezcan, la validez de los estudios hechos en los diversos países hispano-americanos y en otras naciones extranjeras, por los estudiantes españoles emigrados, así como el reconocimiento y convalidación de los títulos que en los diversos grados de la enseñanza hayan podido obtener, siempre que se hallen expedidos por centros oficiales, o que tengan este carácter y sean de reconocida solvencia científica.

19. Es necesario proseguir la obra de las Misiones pedagógicas tan admirablemente desarrolladas por la República con el objeto de llevar a todos los rincones de España, no precisamente conocimientos, sino aquella gracia del espíritu que constituye la esencia del goce más depurado y de la dignidad humana; poniéndolas bajo la advocación de su creador don Manuel B. Cossío.

\section{PRIMERA ENSEÑANZA}

1. Estimamos de cardinal importancia todo lo referente al mejoramiento y selección del personal docente en ejercicio y a la formación del personal nuevo. Ello supone la reforma de las Escuelas Normales y el desarrollo de las Secciones y Seminarios de Pedagogía de las Universidades de Madrid y de Barcelona. La formación del personal docente estará encomendada a estas instituciones. 
2. La formación de los maestros de primera enseñanza dependerá de las Escuelas Normales. Para su reforma se tomará como ejemplo el régimen interino establecido durante la República en la Escuela Normal de la Generalidad de Barcelona. Para el ingreso en las Escuelas Normales se exigirá haber aprobado los cinco años comunes del Bachillerato.

3. Los cursos realizados sobre las prácticas de una escuela elemental que forma parte de la Normal y constituya su célula fundamental durarán tres años: dos en el seno de la Normal y uno al frente de una escuela, bajo la vigilancia directa de la Normal de origen y de la Inspección. Tras estos cursos y prácticas los alumnos se hallarán en posesión de una escuela.

4. Las plazas de cada escuela normal serán restringidas y adecuadas en número a las necesidades del país.

5. Los Inspectores, los profesores de Escuela Normal, los Directores de Escuelas graduadas de más de cinco grados, los Inspectores generales, los Profesores de Pedagogía de las Universidades y los Profesores de escuelas especiales, se formarán en las Secciones y Seminarios de Pedagogía de las Universidades de Madrid y de Barcelona de cuya organización hablaremos en el apartado referente a Universidades. Los Inspectores primarios, los Profesores de Escuela Normal, los Directores, de escuelas graduadas y los Profesores de escuelas especiales deberán ser Licenciados en Pedagogía. Los Inspectores generales y los Profesores de las secciones de Pedagogía de las Universidades, habrán de tener el título de Doctor.

6. Para proveer a la acción tutelar sobre los maestros y al perfeccionamiento de los existentes, es preciso crear gran número de plazas de Inspectores, hasta conseguir que haya uno al frente de núcleos reducidos de escuelas, a fin de que éstas no sean sólo visitadas por fórmula o con meros propósitos inquisitivos, sino con ideales pedagógicos y con eficacia educadora. El número de escuelas asignado a cada Inspector no debe sobrepasar a aquel que haría ineficaz su función directora y orientadora.

7. Debe desarrollarse el cuerpo de Inspectores generales organizado por la República para que intensifiquen y tutelen constantemente la acción pedagógica y moral de los Inspectores primarios. La inspección ge- 
neral actuará con funciones ejecutivas previa reglamentación correspondiente inspirada en ideales estrictamente pedagógicos. Mientras no se haya llegado a su promoción normal, serán seleccionados mediante ejercicios teóricos y prácticos entre los Inspectores primarios o entre personas de excepcional competencia.

8. La enseñanza primaria deberá ser gratuita y obligatoria. Para hacer efectivas estas dos condiciones se habrá de atender a la concesión de recursos a los padres o tutores de los alumnos en circunstancias y casos justificados, de manera que no padezca la asistencia de los niños a la escuela.

9. Para que la enseñanza sea eficaz, es preciso proseguir la política de aumento de sueldos iniciada por la República, sobre todo de los sueldos menores y proceder a un arreglo del escalafón.

10. Previas estas condiciones hay que proseguir el régimen de creación de escuelas iniciado por la República hasta llegar a proveer a todas las necesidades del país. El censo escolar de España es de unos 3,500.000 niños. Antes de la República creó escuelas para más de $1,000.000$ de niños, aproximadamente. ${ }^{18}$ Es preciso llegar a cubrir el cupo escolar completo, atendiendo a todos los niños de edad escolar, es decir, desde los 3 hasta los 14 años.

11. Hay que insistir en la política de construcciones escolares tan brillantemente emprendida por la República, hasta lograr que todos los niños puedan alojarse en locales sencillos e higiénicos, y velar singularmente por las construcciones escolares de las grandes ciudades donde las necesidades higiénicas son más urgentes. Para ello es preciso destinar presupuestos suficientes y proceder a la capitalización de los alquileres en todas las poblaciones grandes.

Se restablecerán y mejorarán las disposiciones que la República estableció con el fin de armonizar la colaboración del Estado y de los Municipios, para emprender sin demora la construcción de los edificios necesarios, teniendo en cuenta su función pedagógica y asegurando para ello la asesoría técnica de pedagogos e higienistas con amplio criterio en las Comisiones de Construcciones Escolares.

\footnotetext{
${ }^{18}$ En el original «para 1.000.000 de niños más, aproximadamente».
} 
12. Las escuelas de nueva creación deberán ser distribuidas de modo adecuado, tanto en el campo como en la ciudad, para hacerlas fácilmente accesibles.

13. Nunca se insistirá bastante en la reorganización de las escuelas rurales, llevando ${ }^{19}$ a ellas con sueldos especiales a los maestros de superior calidad que lo soliciten, los cuales, por este hecho, ascenderán en sus puestos, creando asi escuelas rurales modelo y organizando convenientemente los horarios de acuerdo con las necesidades regionales y locales.

Se continuará la labor iniciada en ellas por la República, dotándolas de bibliotecas públicas y circulantes, talleres, aparatos de proyección, de radio, de reproducción de discos musicales escogidos, de manera que la escuela llegue a constituir un factor básico en la vida espiritual y social del pueblo.

14. Donde hay más de dos maestros se procederá a distribuir los alumnos en las aulas en un principio de graduación.

15. Hay que mantener la extensión de la edad escolar hasta los 14 años, tal como lo estableció el Gobierno de la República, con excepción de aquellos alumnos que aspiren a cursar estudios de segunda enseñanza.

16. Será preciso atender con especial interés a la creación de escuelas de párvulos en crecido número. Aparte la beneficiosa función que desempeñan tales centros desde el punto de vista pedagógico y social, no debe olvidarse que es en ellos donde las conquistas técnicas pedagógicas han calado más hondo. Las demás escuelas en todos los grados, se habrán de beneficiar del tono pedagógico y de la labor de esta primera etapa escolar que ha servido de base de renovación progresiva.

17. Se fomentará asimismo el establecimiento de escuelas maternales generales y especiales análogas de las que funcionaban en Bermeo.

18. Se atenderá especialmente a la educación de los niños que se hallen en circunstancias anómalas a consecuencia de los desastres de la guerra y la represión ulterior.

${ }^{19}$ En el original «levando». 
19. Independientemente de la reorganización y fomento de las escuelas para niños anormales, se establecerán instituciones para niños tracomatosos, ambliopes o débiles visuales.

\section{ENSEÑANZA MEDIA}

1. En la segunda enseñanza existe en España la tradición excelente de los Institutos-Escuela. Ellos fueron el centro de la mejor orientación reformadora. El ejemplo del de Madrid sirvió de modelo para su desdoblamiento en dos secciones y para el establecimiento de tres Institutos-Escuela en Barcelona y de los de Valencia, Bilbao, Sevilla, Málaga, etc. Hubiera sido insensato decretar, de una vez, la conversión de todos los Institutos de segunda enseñanza al nuevo modelo. Sigue naturalmente siéndolo hoy. Se trata de mantenerlos en toda la pureza de su régimen e irlos creando uno a uno a medida que se posean las condiciones de personal y de local suficientes para ello.

Entre tanto hay que ir organizando los demás Institutos introduciendo en ellos las reformas ya consolidadas en los Institutos-Escuela en la medida en que las circunstancias de cada centro lo permitan. Así los Institutos-Escuela seguirán siendo, al propio tiempo, modelo y fermento para la gradual elevación del nivel de la enseñanza media. El ideal es llegar a establecer su tipo como régimen común en todos los Institutos de la Península. Pero hay que medir la distancia entre el ideal y las posibilidades todavía limitadas para la segunda enseñanza en su totalidad.

2. En previsión de la normalización general de aquel régimen, es preciso pensar ya en el establecimiento de nuevos centros de ensayo y reforma. Para ello se instalarán en las Secciones universitarias de Pedagogía, de que hablaremos después, escuelas de primera y segunda enseñanza, directamente dirigidas por el profesorado de aquellos centros. Ellas constituirán los núcleos definitivos para el estudio y la constante mejora del nivel de la enseñanza.

3. Aquí, como en todo, lo primordial es la formación del personal nuevo y la reforma del existente.

Para la formación del personal nuevo, será preciso que todos los licenciados en Ciencias y en Letras que aspiren al profesorado de se- 
gunda enseñanza, ingresen en las Secciones de Pedagogía de las Facultades de Madrid y de Barcelona y que, en su seno, adscritos a los centros escolares por ellas dirigidos, alcancen una formación pedagógica y práctica que les capacite para su cometido. Cuando éso así ocurra, bastará, para ser profesor de segunda enseñanza, el certificado de la Facultad correspondiente. Mientras tanto, la selección se realizará mediante pruebas de carácter teórico y práctico en substitución de las rutinarias de las antiguas oposiciones.

La mejora del personal existente podrá ser llevada a cabo mediante cursillos en las Secciones de Pedagogía, y por la acción tutelar de la Inspección de segunda enseñanza, íntimamente vinculada a aquéllas.

Para alcanzar el título definitivo de Profesor de segunda enseñanza será, en todo caso, necesario, un período de ejercicio provisional tras el cual y previo informe de los directores de los centros en que hayan ejercido y de la inspección y unas pruebas teórico-prácticas complementarias, la Facultad de Pedagogía les otorgará el título definitivo.

4. Se proseguirá la organización de la Inspección de segunda enseñanza iniciada por la República.

5. Lo mismo aquí que en el profesorado universitario será gradualmente extinguido el antiguo escalafón y substituído por una jerarquía de tres grados. Para pasar de una a otra, habrá que demostrar que se es acreedor a ello mediante la exposición razonada del trabajo realizado en la etapa anterior. Se establecerá, además, una correlación entre ambos escalafones, de tal modo que se pueda pasar del uno al otro sin perjuicio de la persona afectada.

6. Como se indicó ya, el límite que de ordinario se establece entre la primera y la segunda enseñanza es algo artificial que carece de razón de ser. No hay solución de continuidad entre las necesidades de una y otra. Ambas tienen el mismo objeto y no pueden tener otro modo de considerarlo y de tratarlo: la formación del hombre en la integridad de su individualidad personal. En ellos es preciso que adquiera toda la cultura necesaria para producir bien su vida en el pleno desarrollo de sus facultades.

Sólo más tarde, y sin perder de vista su carácter esencialmente educador, es posible que su objeto se especialice y dé lugar a un segundo 
grado - el universitario - en el cual a la formación humana se añada el aprendizaje de una destreza profesional o científica.

7. Lo primero, por tanto, es acabar con los restos pseudouniversitarios de la antigua enseñanza secundaria, y organizarla de tal modo que su total contenido no sea sino la continuación y el desarrollo progresivo del espíritu de la escuela de primera enseñanza: suprimir las asignaturas sueltas, estudiadas solamente durante un año y las explicaciones en forma de discurso, así como el aprendizaje exclusivo mediante un libro de texto; el escaso tiempo de contacto del profesor con los alumnos, la falta de larga permanencia de los alumnos en el local y la penuria de recursos educativos fuera del trabajo con libros y lecciones de clase.

8. Frente al trabajo meramente instructivo es preciso implantar una organización que comprenda todas las esferas de la educación humana: permanencia del alumno en el local durante todo el día, haciendo vida escolar de trabajo, de juego, de excursión, de comida si fuese preciso, con sus compañeros y profesores; plena educación intelectual, del sentimiento y del carácter, que abarque desde el pensar y el discurrir hasta la limpieza corporal y el refinamiento de las maneras, y la armoniosa salud del cuerpo y del espíritu, para lo cual no hay factor más eficaz que el que proporciona la continuidad de comunión con el medio más sano posible en todos los momentos de la actividad, desde el trabajo más severo hasta la función al parecer más nimia y subalterna.

9. La enseñanza por asignaturas ha de ser substituída por una distribución concéntrica de los asuntos, entendiendo por tal aquella en que se traten todos con más o menos intensidad, durante varios años. La diferencia consistirá sólo en el cómo y en el cuánto.

10. En el trabajo de clase es preciso substituir la conferencia oral por el coloquio y la comunión personal que ejercite el pensamiento y el trabajo personal, y fuera de clase, mediante lecturas y redacciones numerosas durante las horas de estudio.

11. Para ello es preciso que la clase no exceda de 30 a 35 alumnos. Estos permanecerán en el centro no sólo para las clases, sino también para todos los trabajos personales, los juegos y las diversiones. 
12. El tiempo de permanencia en el Instituto, para el trabajo, ya personal, ya en clase y para el juego en común, podrá variar desde los primeros a los últimos años, entre las siete a las nueve horas diarias. Ello supone la supresión del trabajo en el hogar o su limitación al mínimum estrictamente indispensable.

13. En caso alguno se separará la acción docente de la educadora. Todo profesor, sea de la categoría que quiera, tendrá las horas de trabajo que le correspondan según el plan de estudio y el régimen del centro, no debiendo exceder aquéllas de cinco diarias aproximadamente, ya en clases, estudios, laboratorios, excursiones, juegos, etc. No es necesario que todos los profesores tengan las mismas horas de trabajo, pero será. retribuído no sólo en razón de su categoría, sino también del tiempo de trabajo que preste.

14. En los programas, al lado de una formación intelectual completa figurarán: arte, música, trabajos manuales y educación física efectivas.

15. En principio todos los ciudadanos tienen el mismo derecho a una formación que dignifique su vida, sin que ella dependa de su condición económica. Para satisfacer, en la medida de lo posible, las exigencias de la justicia social es preciso extender, dentro de la selección intelectual indispensable, el carácter gratuito de la segunda enseñanza y, hasta donde sea posible, organizar un sistema de becas para la vocación y la competencia. Para aquellos que no puedan asistir a las clases ordinarias por impedirlo su trabajo diurno, hay que organizar clases especiales a horas extraordinarias y convenientes.

16. Es preciso suprimir toda clase de exámenes, de acuerdo con una tradición española excelentemente orientada. Los profesores de cada clase y el claustro general decidirán de las aprobaciones sin más ejercicios que los resultados del trabajo diario y el conocimiento personal de la formación de los alumnos.

En cuanto a los alumnos de establecimientos privados los exámenes serán de conjunto, y consistirán en ejercicios muy varios y razonados, escritos, sobre todo, orales y prácticos, encaminados especialmente a concluir con la repetición del texto y el puro memorismo. 
17. Para el paso de la primera a la segunda enseñanza, todas las clases de primer año deben funcionar normalmente con los aspirantes durante un corto período, antes de empezar el curso, y al final del ensayo el claustro de profesores deliberará y decidirá sobre la admisión o exclusión de cada uno de los alumnos. Para esta decisión se tendrán en cuenta los informes de la Escuela de que procedan y de los Institutos de Psicotecnia, en caso necesario.

18. Es necesario mantener y acentuar la elevación de la edad del Bachillerato, haciendo que los estudios de segunda enseñanza no terminen hasta los 17 ó 18 años.

Sólo así alcanza sentido el problema del bachillerato único o de varios bachilleratos. Esto supuesto, es preciso dividir el bachillerato sólo a partir de los 15 años, estableciendo un primer período común, el más largo, para todos los alumnos, y un período más corto en el cual, sin abandonar los demás asuntos, se inicie gradual y prudentemente el predominio de aquellos que libremente el alumno quiera cultivar de acuerdo con su interés, vocación y aptitudes.

Este sistema optativo debe fomentarse en gran escala, ofreciendo para ello gran número de asuntos y gran libertad, y no perdiendo de vista que, si bien en el primer período predomina el carácter general y común sobre la distinción de aptitudes especiales, éstas no surgen como por encanto o de modo súbito y mecánico. Tienen su asiento, desde un principio —casi siempre en estado latente y caótico- en lo más íntimo de la naturaleza humana; y el fin de la educación es promoverlas y descubrirlas, cultivando, en medio y al par que lo humano, el especialista que hay siempre. en el hombre.

19. De ahí la necesidad de extender los programas de segunda enseñanza no sólo a todas las ramas de la cultura intelectual, sino de introducir también en aquel horizonte una serie de labores manuales, cuanto más varias mejor, rudimentos de oficios que formen como el abecedario de las industrias en sus diversas ramas y el contacto con las cuales, aparte el desarrollo del espíritu a través de la mano, habrá de servir para despertar las aptitudes orientadas hacia semejante esfera, y rehabilitar a la misma del injusto menosprecio con que el viejo intelectulismo suele considerarla. 
20. Así, el Bachillerato constará de siete cursos. En los dos o tres últimos se especializará en tres direcciones: literaria, científica o politécnica.

21. En los últimos cursos, una parte del tiempo será dedicado a la especialidad, y el resto, optativamente, a los asuntos de las otras secciones. Al bachillerato politécnico se le concederá la misma atención, dignidad e importancia que a los de Ciencias y Letras.

22. En todo caso, el título de bachiller será único, y habilitará para cualquier tipo o especialidad de estudios superiores.

23. El griego y el latín, que deberán estudiarse con toda la amplitud e intensidad que la experiencia acredite como necesaria para que los alumnos lleguen a dominarlos, serán siempre facultativos. Para todos serán sólo necesarias unas nociones elementales de latín en relación con la enseñanza básica del idioma propio.

Para los que escojan las enseñanzas clásicas debe tenerse en cuenta que su eficacia depende de que se las pueda utilizar para el conocimiento de las respectivas culturas. La virtud formativa que se les atribuye es sólo, en el fondo, filosofía o ejercicio del pensamiento especulativo, lo cual no depende del asunto, sino de la disposición con que el asunto se afronta. Toda enseñanza puede ser humana y humanista, si su dirección responde a este propósito.

Se reorganizará el estudio a fondo de una o dos lenguas vivas, según la proporción en que se haya escogido el estudio de las lenguas clásicas.

24. El internado es siempre un mal menor. Malo es, en general, siempre, sustraer al niño de las condiciones familiares. Dado que es necesario, sin embargo, organizarlo para las familias que residen lejos de los centros de segunda enseñanza, es preciso hacerlo, dentro de la medida de lo posible, en casas dirigidas por familias de los mismos profesores, con sus propios hijos y siempre con reducido número de niños internos. Para ello, tanto las casas como las familias de los profesores necesitan ofrecer garantías de muchas clases y muy especiales. Cuando ésto no sea posible, se organizarán residencias que se acerquen lo más posible al carácter familiar. 
25. Esto supuesto, la primera obligación del Estado es procurar con premura y ahinco que sus establecimientos oficiales de enseñanza sean, en material, edificios, personal y régimen educativo, superiores a todos los demás.

26. De suma importancia es el restablecimiento y reorganización de las Escuelas elementales del trabajo, de las Escuelas industriales medias y de las Escuelas de Artes y Oficios, tal como existían, de acuerdo con los ideales que las animaron y su extensión a otras ciudades industriales de España, desarrollando, así, la magnífica tradición del artesanado español. Para su correlación posible con el Bachillerato, se acentuará en sus programas el aspecto de formación general y humanística.

27. En la misma forma es preciso prodigar el establecimiento de escuelas elementales y medias de agricultura y zootecnia, conformando su organización a la especial característica de las zonas y a la especialidad de sus cultivos.

28. En íntima conexión con lo anterior, es urgente establecer en los lugares adecuados, recogiendo la rica tradición nacional, escuelas y conservatorios que tiendan al fomento y adecuada depuración de las Bellas Artes populares en todas sus formas.

29. Intimamente vinculada a esta tarea de orientación y realización, se halla el restablecimiento y adecuada dotación de los Institutos psicotécnicos de Madrid y de Barcelona, con sus Escuelas prevocacionales y la adecuada distribución de centros subordinados de orientación y selección profesional, extendidos por todo el territorio del país.

\section{CULTURA SUPERIOR}

\section{A) Universidades y Escuelas superiores}

1. Es preciso tener en cuenta para todas las reformas, que los fines esenciales de la enseñanza superior son: la investigación científica, la reforma profesional y el mantenimiento y desarrollo de un nivel de alta cultura en el país.

2. Se procurará reanudar las actividades del Consejo de Cultura de la República, a fin de acelerar la implantación de los proyectos elaborados con las adaptaciones que las circunstancias impongan. 
3. Dentro de tales proyectos merece destacarse el esfuerzo realizado para aproximar la Universidad y coordinar con ella la organización docente de las Escuelas superiores de Ingeniería, Arquitectura y similares.

4. Se reconoce la obligación de haber cursado el Bachillerato para aspirar al ingreso a cualquiera de ellas y seis años del mismo, incluída la educación cívica, para entrar a formar parte de la oficialidad del ejército y de la armada, según lo establecido por la República.

5. Se estima conveniente procurar que las materias no especificadas de la técnica militar sean estudiadas en las Universidades; así, el primer curso de matemáticas que figura en el plan de estudios y, para su formación espiritual y ciudadana, el curso general de Historia de España o de la Civilización española, y una introducción general a la Filosofía, dando preferencia en ésta a los problemas de la Psicología colectiva, a la Lógica en íntima conexión con la formación matemática y con vistas a la educación del intelecto en el rigor de la exposición y del discurso - y la Etica - con insistencia en la formación ciudadana y en la íntima convivencia de los diversos sectores de la vida nacional, y como base para el estudio de la moral específicamente militar.

No menos importante que el estudio de estas disciplinas habrá de ser el asiduo cultivo de la convivencia con los estudiantes de las más diversas profesiones. Para asegurar su benéfico influjo será preciso que el estudiante participe activamente en la vida social de la Universidad, asistiendo y colaborando en conferencias, visitas, excursiones, reuniones, comidas en común, deportes, etc.

6. Se procurará una más íntima coordinación de las Facultades con la tendencia a lograr la unidad de la vida y de la formación universitarias en relación con las Facultades de Filosofía y Letras y de Ciencias.

7. Se buscará asimismo el mejor modo de vincular en cada caso con la vida de las Facultades respectivas, los estudios de las Escuelas profesionales, no sólo de Ingenieros y Arquitectos, sino también las de Comercio, Funcionarios, Auxiliares de Bibliotecas, Archiveros, etc.

8. Las Escuelas de Ingenieros y Arquitectura y Comercio, aparte su más íntimo contacto con la Universidad, se vincularán a las Escuelas de Trabajo e Industria y a las Escuelas de Agricultura y Zootecnia en todos 
sus grados con la tendencia a llegar gradualmente a formar con ellas un todo graduado y coherente.

9. Se fomentará la creación y el desarrollo de escuelas especiales de Funcionarios, de Auxiliares de Bibliotecas y Archivos, etc., coordinadas con las respectivas Facultades.

10. La autonomía universitaria, con tanto éxito implantada en la Universidad de Barcelona y que habrá de mantenerse en la misma, no podrá ser medida general, sino aspiración progresiva, ensayando, hasta llegar a ella, distintos grados de tutela, según las condiciones de cada centro.

11. Sería, desde luego, conveniente, su implantación en la Universidad de Madrid, que cuenta ya con el feliz ensayo realizado en la Facultad de Filosofía y Letras.

12. Se considera un deber histórico y nacional, iniciar el esfuerzo necesario que restituya a Salamanca el prestigio universal de que gozó como ciudad universitaria. Ensayos y reformas cuidadosamente dirigidos, pueden ir haciendo que, gradualmente, este ideal se transforme en realidad.

13. Se señala la conveniencia de que los Patronatos de las Universidades autónomas mantengan entre sí las relaciones más estrechas que las circunstancias permitan.

14. Se fundará una Junta Central de Universidades que con la autonomía debida tenga a su cuidado el fomento de la reforma, y la coordinación y tutela del resto de las Universidades peninsulares.

15. Será considerado como necesidad nacional el restablecimiento, en Madrid y Barcelona, de los Seminarios y Secciones de Pedagogía, en los que habrá de contribuirse a la formación del personal superior de la enseñanza en todos sus grados, continuando la labor iniciada durante la República.

16. Función esencial de esos Seminarios y Secciones de Pedagogía será la formación humanística y técnica de los funcionarios de la primera enseñanza -inspectores primarios y superiores, profesores de escuelas normales, directores de grupos escolares de más de seis grados y de enseñanzas especiaalizadas- dirigir la formación pedagógica del 
profesorado de enseñanza media, y cooperar a la de los profesores de estudios superiores.

17. Las Secciones y Seminarios pedagógicos estarán instalados en el seno de un Instituto-Escuela creado ad hoc, con el objeto de que la formación teórica, la investigación y la especulación tengan su raíz en la realidad viva de la educación.

18. Con el mismo objeto mantendrán, además, el más estrecho vínculo con los establecimientos de enseñanza del país para la formación del profesorado de la primera y segunda enseñanza y para la superior, con el resto de las Facultades y Secciones universitarias.

19. Para la selección del profesorado universitario se seguirán las normas establecidas durante la República, desarrollándolas y mejorándolas, y procurando que las personas encargadas de aplicarlas las cumplan no sólo en su letra, sino también en su espíritu.

20. Deberá transformarse la función del profesorado auxiliar en tanto que simple substituto del titular, dándole, en cambio, una intervención efectiva en la vida universitaria, aumentando su número y matizándolo en una serie de jerarquías y funciones que permitan a su ejercicio convertirse gradualmente en la base para la selección del profesorado titular. Para ello podrá servir de ejemplo lo ya realizado en la Facultad de Filosofía y Letras y de Medicina de Madrid y en la Universidad Autónoma de Barcelona.

21. A pesar del carácter temporal de este profesorado, será necesario establecer y reglamentar un mínimo de pruebas que unifiquen y garanticen su ingreso.

22. Cuando un profesor de otro grado de enseñanza alcance categoría universitaria por las razones que se consideren justificadas, se tendrán presentes los servicios que al Estado lleve prestados, reconociéndole la antigüedad correspondiente.

23. Mediante una conveniente reorganización de los Centros de Enseñanza Universitaria, se tendrá que evitar la penosa experiencia de que algunas de nuestras Universidades no ejerzan sobre los profesores sino una atracción transitoria y en consecuencia, se establecerán mínimos de permanencia que, salvo casos excepcionales y bien probados, asegu- 
ren la continuidad científica y el prestigio de todos los Centros Universitarios.

24. Será preciso establecer con mayor precisión los deberes de los profesores en todos sus grados y categorías, vinculándolos más estrechamente a la vida universitaria. Es necesario garantizar un mínimum de permanencia en las labores docentes y educativas, colocando los sueldos en relación con el grado de atención que se dedique a la Universidad.

25. Deberán otorgarse dotaciones amplias y flexibles para medios materiales de trabajo: Seminarios, Bibliotecas y especialmente Laboratorios de Ciencias experimentales.

26. Será conveniente dar una mayor elasticidad a los planes de estudio, estableciendo un mínimum de enseñanzas básicas obligatorias, dejando en libertad a las Facultades para la organización de enseñanzas complementarias. Un criterio análogo deberá adoptarse para reglamentar con la mayor intensidad y efectividad, la enseñanza práctica de las ciencias experimentales.

27. Aun considerando excesivo el número de Universidades existentes en España, salvo casos excepcionales, no estimamos prudente, sin embargo, la simple supresión de varias de ellas, sino que sería preferible buscar la agrupación y concentración compensada de Facultades, Escuelas e Institutos, teniendo en cuenta la índole y la tradición de cada localidad.

28. Se implantará temporalmente la prueba de ingreso en la Universidad, mediante ejercicios adecuados que permitan una selección rigurosa según la capacidad y teniendo en cuenta los antecedentes del Bachillerato. De esta manera, además de asegurar la selección intelectual, se evitará en las Universidades una aglomeración de estudiantes excesiva y perjudicial.

29. Por lo menos durante la etapa transitoria y hasta que el sistema educativo completo empiece a dar sus frutos en todos los grados, cada Universidad procurará suplir las insuficiencias de formación de los estudiantes de nuevo ingreso, organizando breves cursos de iniciación que permitan a los escolares salvar la distancia entre un Bachillerato poco diferenciado y los primeros cursos de las Facultades diversas. 
30. Se extenderá gradualmente, a medida que las circunstancias lo permitan, el régimen de Residencias de estudiantes, de acuerdo con el ejemplo y las experiencias de lo realizado especialmente en Madrid y Barcelona.

31. Es urgente el establecimiento de un sistema de becas amplio y graduado para asegurar que el ingreso y la permanencia en la Universidad sólo dependa de las condiciones intelectuales y morales de los alumnos.

\section{B) Investigación Científica}

1. Es preciso, ante todo, el restablecimiento en sus plenas funciones de la Junta para Ampliación de Estudios e Investigaciones Científicas y de todos los Centros de alta cultura e investigación que existían en España antes del actual régimen; ayudar a las Universidades que habían establecido Seminarios, Institutos, Laboratorios de Investigación a que los puedan restablecer en sus funciones y desarrollarlos organizando una cooperación que los armonice y contribuya a su eficacia.

La Junta para Ampliación de Estudios dedicará una parte sustancial de sus medios y de su organización a estudios sobre temas españoles, realizados precisamente en nuestro país. Cuando la índole de las materias lo permita, la realización de trabajos de investigación en España será condición indispensable para la concesión de pensiones en el extranjero.

En ningún caso se concederán pensiones para otros países sin acreditar plenamente un dominio suficiente de la materia que será objeto de ampliación, así como un conocimiento suficiente del idioma del país respectivo.

2. En los Seminarios y Centros de Investigación Universitaria podrá haber profesores consagrados preferentemente a dicha labor y descargados de otras labores docentes de carácter más general o elemental.

3. En relación con la investigación científica se organizará la continuidad del trabajo de los postgraduados, becándolos adecuadamente y poniendo su labor en conexión con las tareas auxiliares de los seminarios y de tutela de los alumnos. 
4. Es preciso dedicar especial atención a la publicación de los resultados de las investigaciones científicas.

Se fomentará el establecimiento de Editoriales universitarias que publiquen especialmente trabajos de extraordinaria valía científica, pero no comercial, así como las obras instrumentales que nunca debieran ser abandonadas a las empresas lucrativas, y, las grandes publicaciones de síntesis culturales que sean una pieza de nuestra política cultural exterior.

5. Al lado de la investigación pura y en íntima correlación con ella, con los Institutos, Universidades y Escuelas superiores, se establecerán o desarrollarán Centros de Investigación aplicada y técnica, nacionales, regionales y comarcales para contribuir al fomento y a la mejor explotación de la riqueza nacional. En este sentido, cabe indicar, por vía de ejemplo, el desarrollo de uno de varios Institutos de Alimentación y Centros encargados de la investigación y de mejora de las razas merinas y de los problemas de la industria lanera en Extremadura y Aragón, de los cereales e industrias derivadas, en Castilla; de los productos de los lignitos en Aragón, de la industria metalúrgica, aceros y aleaciones especiales en Bilbao y Valencia; de maquinaria, tejidos, sosa y potasa, en Cataluña y los países vascos, de los problemas relacionados con los saltos del Duero; del corcho, de las plantas medicinales, así como de la pesca e industrias derivadas - aceites, residuos, etc.- y de las conservas en todas sus formas — de pescados, de frutas y legumbres, de carnes, etc.-.

\section{c. Tesoro histórico-artístico y científico y servicios de Archivo, Bibliotecas y Museos}

1. La administración pública, siguiendo la labor iniciada por la República, deberá intensificarla, organizando eficazmente la salvaguarda y defensa del patrimonio histórico-artístico y científico, con los servicios adecuados de archivos, bibliotecas y museos, monumentos, excavaciones, etc.

Ninguna organización política o social utilizará en ningún ${ }^{20}$ caso los tesoros de nuestra cultura tradicional para finalidades que puedan atraer sobre ellos una acción destructora.

\footnotetext{
${ }^{20}$ En el original «ningúún0187,
} 
2. Aquella parte del tesoro histórico-artístico y científico (edificios, zonas arqueológicas, obras de arte, colecciones científicas, parques, jardines, bosques, etc.), que deba ser mantenido por sus poseedores habrá de serlo en condiciones de fácil accesibilidad y estudio, procediéndose, cuando ésto no se cumpla o cuando sea necesario para mejor conservarlos y aprovecharlos, a su inmediata incautación, sin perjuicio de seguir ulteriormente los procedimientos a que den lugar las indemnizaciones adecuadas que la ley determine.

3. En cuanto al servicio de archivos y bibliotecas, además de proseguir la activa tarea de reorganización, tan brillantemente emprendida por la República en lo que se refiere a los grandes centros, cuidará muy especialmente del establecimiento de Bibliotecas populares que cooperen a la obra de difusión de la cultura en todos los sectores y en todos los ámbitos del país. Para ello podrá seguirse el ejemplo de la obra realizada por la Escuela de Bibliotecarias de la Mancomunidad y la Generalidad de Cataluña.

Al frente de los archivos y bibliotecas se pondrán, con la mayor estabilidad posible, técnicos probados que, con loable sacrificio de su capacidad investigadora, dediquen todos sus esfuerzos a la patriótica tarea de hacer accesibles y plenamente útiles los fondos de esas instituciones a los investigadores especializados.

4. Las grandes bibliotecas y las de tipo especializado serán accesibles a todos, y se proseguirá en ellas la obra de modernización tan eficazmente emprendida en las mejores de Madrid y de Barcelona.

Se fomentará el intercambio, convenientemente garantizado, de los fondos científicos entre las grandes bibliotecas y se les dotará de un bien organizado servicio de microfilms, subvencionado por los poderes públicos, exigiendo tan sólo de los usuarios unas tasas simbólicas de aprovechamiento. 


\section{INTERCAMBIO UNIVERSITARIO ${ }^{21}$ Y RELACIONES CULTURALES, ESPECIALMENTE CON AMÉRICA}

1. Se fomentará el intercambio internacional de profesores, investigadores y estudiantes con los países extranjeros, así como la colaboración española en los progresos y empresas científicas intemacionales.

2. Se continuará, desarrollará y coordinará la política de pensiones al extranjero para profesores y alumnos.

3. Es necesario persistir y desarrollar, de acuerdo con la orientación iniciada por la República, la creación de escuelas e instituciones en aquellas poblaciones, fuera de España, en que haya colonias de españoles residentes o de origen o habla española.

4. Es preciso realizar la intima conexión de los Institutos ya existentes de estudios hebreos y arábigos con los países en que funcionen centros análogos y especialmente con los de los pueblos islámicos.

5. Se restablecerá en su pleno funcionamiento la Universidad de Verano de Santander y las demás universidades de verano para extranjeros establecidas en España, y se seguirá la empresa de viajes de estudio por España y el Extranjero como el que realizó en torno al Mediterráneo la Facultad de Filosofía de Madrid y que tenía en vía de organización la de Barcelona, así como el del Instituto oceanográfico y otros análogos.

6. Todos los países de habla española, incluidos Portugal y el Brasil, han de ser objeto de una especial predilección de acuerdo con nuestras posibilidades económicas y con las siguientes orientaciones:

a) Aumento y creación de gran número de pensiones y becas —estudios gratuitos, manutención, viajes, instalación en Residencias de estudiantes, etc.- para estudiantes y postgraduados.

b) Intercambio en gran escala de profesores y alumnos con dotaciones para los que deseen realizar estudios en los países de habla española o portuguesa.

c) Organización de cursos y conferencias a cargo de personalidades eminentes.

\footnotetext{
${ }^{21}$ En el origuinal «UNVERSITARIO».
} 
d) Fundación de Residencias de estudiantes organizadas con modestia y decoro.

e) Establecimiento de Instituciones de cultura de todos los grados, en íntima colaboración con los elementos del país en que se establezcan, con la misión de que sean centros de difusión en América del movimiento intelectual de España, y con la aspiración de que en algunos de ellos puedan servir de base para la creación de centros de investigación mantenidos por España.

f) Publicación de Revistas científicas y de cultura en España y en los demás países de colaboración hispanoamericana.

g) Celebración frecuente de congresos hispanoamericanos de diversas especialidades y reuniones científicas y culturales de más íntima colaboración.

h) Organización frecuente de exposiciones de arte, conciertos, etc., de intercambio y colaboración.

i) Estudio de las condiciones necesarias para establecer el reconocimiento de los títulos académicos y profesionales en un plano de estricta reciprocidad.

j) Obligación de los profesores españoles, las colonias de emigrados de nuestra patria y las representaciones diplomáticas y consulares, de velar porque los grupos de españoles en el extranjero y en particular sus descendientes reciban una sólida cultura de nuestro idioma, nuestros valores tradicionales y nuestras posibilidades futuras.

k) Estudio de un meditado plan de investigaciones hispanoamericanas, asegurando los medios económicos, elementos intelectuales y auxiliares para llevarlo a cabo de acuerdo con los países de Hispano-América.

l) Fundación de un Instituto de Intercambio Económico y Social Hispanoamericano para comunicar entre los gobernantes de nuestros países sus experiencias y proyectos, valorando mutuamente con organismos consultivos, las iniciativas de los respectivos especialistas. Un servicio de bien conectados observatorios asegurará una auténtica y útil información sobre las condiciones de vida y desarrollo en nuestros países. 
11) Revisión de los planes y programas de la Historia en los centros de enseñanza de acuerdo con los países hispanoamericanos, con el objeto de conseguir, dentro de los límites de la verdad, una comprensión unitaria de los acontecimientos; no olvidando que en país alguno ha dejado de haber guerras, conquistas y luchas civiles; abandonando, sin perjuicio de la crítica serena, la inútil y morbosa obsesión de convertirnos en jueces y censores de nosotros mismos y de los demás, recordando que, si se la mira con gesto de generosa comprensión, en nuestra Historia, como en todas sin excepción, lo grande se mezcla con lo abyecto y que, si se la considera en su trayectoria total, es una de las más ilustres entre todas las que se han desarrollado sobre la faz de la tierra.

\section{Voto particular}

Los artículos 3 y 4 de II GENERALES, de la Ponencia, fueron modificados y refundidos en uno. El ponente doctor Joaquín Xirau mantuvo el texto primitivo y lo convirtió en voto particular formulado en los siguientes términos:

«3. En las enseñanzas primarias y media se considera necesaria la explicación de la Filosofía y la Religión —especialmente la cristiana- desde un punto de vista histórico, con el respeto que merecen su dignidad en el espíritu y la cultura».

«4. La enseñanza religiosa confesional pertenece a las Iglesias y se dará con toda libertad fuera de los centros de enseñanza».

D. Francisco Giral se adhirió al voto particular.

\section{Nota sobre el autor}

José Ignacio Cruz Orozco es Doctor en Filosofía y Ciencias de la Educación (1987). Profesor Titular de Universidad en el Departamento de Educación Comparada e Historia de la Educación de la Universitat de València desde 1992. Especialista en historia y en política de la educación. Sus líneas de investigación fundamentales son: el sistema educativo español, la educación secundaria y políticas de juventud. Tiene reconocidos dos 
tramos de investigación (sexenios) y cuatro tramos de actividad docente (quinquenios). Ha publicado una quincena de libros entre los que se encuentran: El yunque azul. Frente de Juventudes y sistema educativo. Razones de un fracaso, Madrid: Alianza, 2001; Los colegios del exilio en México, Madrid: Residencia de Estudiantes, 2005; Prietas las filas. Las falanges Juveniles de Franco, Valencia: Universitat de València, 2012; La cultura académica del exilio español en México: Viejas prácticas para nuevos tiempos, México: UAEH-Universidad de Valencia-Díaz de Santos, 2013 (editor conjuntamente con Leticia Canales Rodríguez); Consideraciones sobre la enseñanza secundaria española (1835-1970), en Tavares Santos, J.M., Regina Paz, S. (2013) Enseino Médio: Profissao Docente, Currículo e Novas Tecnologías, Curitiba: CRV, 245-260. Asimismo, ha publicado más de sesenta artículos sobre diversos aspectos de la educación española en diversas publicaciones especializadas españolas y extranjeras, entre los que cabe señalar: «Los institutos de segunda enseñanza en España. Datos sobre su implantación (1835-1936)». Educatio Siglo XXI 30, no.1 (2012): 233-252; «La extensión de la Enseñanza Media en la España rural. Los Colegios Libres Adoptados (1960-1980)». Revista Española de Pedagogía 256, (2013): 293-308.

\section{REFERENCIAS}

Alted Vigil Alicia y Roger González Matell. «Científicos españoles exiliados en Cuba». Revista de Indias 22, no. 224 (2002): 173-194.

Alted, Alicia. La voz de los vencidos. El exilio republicano de 1939. Madrid: Aguilar, 2005.

Dosil Mancilla, Francisco Javier. «La JAE peregrina». Revista de Indias 57, no. 239 (2007): 307-332.

Francisco Giral, «Actividad de los gobiernos y de los partidos republicanos», en El exilio español de 1939, vol. II, dir. José Luis Abellán (Madrid: Taurus, 1976), 204-207.

López Sánchez, José María. «El exilio científico republicano en México: la respuesta a la depuración». En La destrucción de la ciencia en España. Depuración universitaria en el franquismo, dir. Luis Enrique Otero Carvajal, 177239. Madrid: Editorial Complutense, 2006.

Luis Martín Francisco de. La FETE (1939-1982). De la represión franquista a la transición democrática. Madrid: Tecnos, 2009. 
Martín Ramos, José Luis. «La Unió Socialista de Catalunya (1923-1936)». Recerques: Història, economia i cultura 4 (1974): 155-190.

Nogueroles Jové, Marta. «La propuesta pedagógica de Joaquín Xirau». Transatlántica de educación 14-15 (2015): 41-53.

Otero Urtaza, Eugenio. «Los marineros del entusiasmo en las Misiones Pedagógicas». En Las Misiones Pedagógicas, 1931-1936, editado por Eugenio Otero Urtaza, 64-113. Madrid: Sociedad Estatal de Conmemoraciones Culturales-Residencia de Estudiantes, 2006.

Pereira, Juan Carlos y Pedro Antonio Martínez. Documentos básicos sobre Historia de las Relaciones Internacionales (1815-1991). Madrid: Editorial Complutense, 1995.

Rangel Mayoral, Modesto Miguel. Rubén Landa Vaz. Un pedagogo extremeño de la Institución Libre de Enseñanza en México. Mérida: Editorial Regional de Extremadura, 2006. 